\title{
El papel de la educación en la invención de lo social (o de cómo la historia escolar transformó progresivamente lo social en la Argentina)
}

por

Silvia Finocchio

Facultad Latinoamericana de Ciencias Sociales/Universidad Nacional de La Plata

El artículo propone un recorrido desde mediados del siglo XIX hasta la actualidad, con el propósito de reconocer diversas representaciones y sensibilidades socioculturales y políticas asociadas a la educación en la Argentina. Se trata de un estudio centrado en la prensa educativa, focalizada en la circulación de autores, teorías y métodos que nutrieron la vida escolar. De ese modo, se ponen en contraste intencionalidades pedagógicas y prácticas escolares a través de las cuales el sistema educativo argentino asumió, en su sentido más amplio, la dimensión social.

Palabras Clave: Educación; Argentina; Docentes; Pedagogía.

\section{INTRODUCCIÓN}

El propósito de este artículo es presentar una serie de interpretaciones a partir de palabras e imágenes que, al abrigo de un artefacto cultural tan propio de los siglos XIX y XX como la prensa educativa, pusieron en circulación sentidos políticos y pedagógicos que procuraron poner en cuestión, cambiar o transformar completamente la sociedad argentina.

En las páginas que siguen ofreceré argumentos sobre los modos que adoptó la invención de lo social por parte de la educación y que van desde los sentidos asociados a lo civilizatorio y nacional hasta su reconfiguración casi completa como un corpus de sujetos victimizados. Por tanto, me centraré en 
el análisis de la transformación de los imaginarios que circularon y perfilaron el hacer activado desde la educación.

Antes de comenzar quisiera realizar algunas aclaraciones. En primer lugar, advertir que más allá de reconocer la temprana apropiación de lo educativo por parte del Estado nacional en comparación con otros países de América Latina, pondré entre paréntesis la idea de «epopeya educativa». Esto supone intentar eludir la nostalgia que deshistoriza la posibilidad interrogativa al saturar el devenir con emociones presentes, y esforzarme también en esquivar ciertos sentidos teóricos y perspectivas historiográficas que la propia vida escolar pone en cuestión por la complejidad de sus matrices, así como por la densidad de sus matices.

En segundo lugar, considero conveniente mencionar que entiendo aquí la invención de lo social como un proceso en el que tienen también un lugar central los sujetos y su producción, reconociendo el papel protagónico que ocupan las elecciones que efectúan y los saberes que producen al expresar creencias y preferencias frente a las diversas opciones simbólico-políticas disponibles arrojadas a la conquista celular de la educación.

En tercer lugar, quisiera señalar que la invención de lo social supone un lugar para determinadas tecnologías o artefactos. Estas juegan un papel importante y son indisociables de las líneas del tiempo de lo social. No es posible pensar el mundo educativo sin sus objetos, ya que la cultura material — pupitres, pizarras, plumas, pizarrones, láminas, cartillas, libros, cuadernos, carpetas, lapiceras, televisores, computadoras o laptops - perfila el hacer activado en el interior de la escuela. La educación necesita de tecnologías específicas que cambian de época en época, y estas traen aparejadas representaciones sobre la educación y la sociedad, así como saberes, prácticas y vínculos entre los sujetos.

En cuarto lugar, quisiera especificar que sugiero pensar lo social como un invento asociado a la idea de comunidad imaginada que comparte tanto modos de interpretar como sensibilidades y afectos. Si bien la polisemia es una cualidad de los discursos, la estabilidad interpretativa se sobreimprime. En este caso importa la serie de representaciones y sensibilidades socioculturales y políticas que exceden la situación del aula y la sostienen.

En quinto lugar, y por último, advertir que la escuela en la Argentina, como en Europa, no nació dentro de un sistema gobernado por el Estado, y que lo escolar entendido como un espacio-tiempo social autónomo deviene de una mezcla entre religión y ciencia que los requerimientos de cristianización plantearon en los siglos XVI, XVII y XVIII. Esto obliga a reconocer las experiencias escolares preexistentes al Estado nacional, así como la potencia educativa de las corporaciones, con las que se abrió un proceso de puja y 
negociación alrededor de las definiciones de «escuela pública» y de «libertad de enseñanza». Para el caso argentino, esta puja continúa vigente cada vez que se observan los porcentajes altísimos, en comparación con escalas mundiales, en la privatización de la educación, peso que por cierto se fue incrementando desde los años sesenta del siglo XX y que llega a rondar hoy entre el $35 \mathrm{y}$ el 50 por ciento de matrícula escolarizada por el sector privado en las más grandes ciudades del país.

En síntesis, lo que intento plantear, desde una perspectiva político-cultural, es que lo educativo en tanto situación social, en el sentido más amplio del término, se inventó también en el día a día, en la relación del Estado con las prácticas de los sujetos, produciendo cambios y movimientos en los imaginarios, abriendo un espacio propio en un orden impuesto y haciendo de la práctica cultural cotidiana algo concerniente a las relaciones de fuerza que estructuran el campo educativo.

\section{LA EDUCACIÓN INVENTA LO SOCIAL COMO CIVILIZATORIO}

Actuar por puro respeto al deber, cumplir el deber de la sujeción moral y la educación como estrategia privilegiada de regeneración moral fueron los núcleos de los discursos pedagógicos de Comenio, Kant, Pestalozzi, Herbart, muchos de ellos alemanes, que no solo nutrieron la educación moderna en Europa sino que llegaron a la Argentina como crítica al método de enseñanza considerado «tradicional», el verbalismo memorístico, a partir de la segunda mitad del siglo XIX. La emergencia de una sociedad moderna e independiente, en la Argentina, se encaró mirando a Europa y postulando el ingreso al «mundo civilizado» a través del método intuitivo de Pestalozzi, o la llamada «pedagogía de las cosas». Este método, ideado por Pestalozzi con el fin de educar a los niños pobres, llegó a la Argentina desde Estados Unidos a través del conocimiento directo por parte del propio Domingo F. Sarmiento, y se articuló con diversos fragmentos del discurso positivista, especialmente el primer Comte y el naturalismo biologista de corte spencerianismo ${ }^{1}$. En la definición de sus alcances, por tanto, la educación procuraría combatir la «barbarie», entendida como obstáculo al progreso del país. Y para ello debía, según se desprende de los Anales de la Educación Común - publicación del grupo liderado por Domingo Sarmiento y Juana Manso en la Provincia de Buenos Aires, así como de las publicaciones de las primeras escuelas normales creadas desde 1870 en las diferentes provincias bajo el impulso del Estado nacional- ejercitar

\footnotetext{
${ }^{1}$ Ossenbach, 1997: 353-366.
} 
el razonamiento moral, esto es, formar el carácter o la personalidad, siendo esta una de las tareas fundamentales de quienes enseñaban. Se tendía así a la reducción de la cantidad de contenidos educativos, considerando que era más importante la formación de la mente, la creación de hábitos, la formación de sentimientos morales y sociales y el fortalecimiento de la salud física del niño.

Cuando el Estado nacional, acompañado por otros actores como las asociaciones docentes, comenzó a impulsar con mayor fuerza la misión de asimilar culturalmente una sociedad crecientemente cosmopolita debido al fenómeno inmigratorio, no procuró tanto una nación homogénea como una «moral homogénea», que estableciera un único modo de ser varón, mujer, configurar una familia, encontrarse y saludarse en la calle, hablar y jugar con amigos, vestirse y arreglarse. Por eso, la escuela debía enseñar a toda hora deberes morales. Porque se quería un mismo patrón para todos. Y por eso se presentaba un mundo ordenado según esquemas precisos que relacionaban moralidad, vida práctica y orden público. Una idea de virtud que confundía civilidad con ciudadanía, prometiendo felicidad y progreso para la humanidad toda.

Las políticas estatales constituyeron un espacio de ardua promoción de la responsabilidad de la escuela pública de educar a niños y niñas, así como de persuasión para que las familias enviaran a sus hijos e hijas a ella. Decía Juana Manso, sucesora de Sarmiento en la dirección de los Anales y en diversas tareas públicas: «Nosotros no vamos a hacer escuelas para continuar las tradiciones de la barbarie, sino para demoler el rancho y desterrar el chiripá, vamos a plantear escuelas, para que el hombre del campo no sea de hoy en adelante el paria desheredado de la familia argentina, sino el ciudadano apto a dejar el arado, para empuñar el bastón del mando; para que deje de ser la maza ciega de la culpable ambición de los caudillos, y sea antes el celoso guardián de las leyes de su país» ${ }^{2}$. Se aludía al niño como a un adulto en potencia. De allí, la capacidad civilizatoria que se le asignaba a la educación, en el futuro del progreso social, a través de un niño que al asistir a la escuela primaria se convertiría en agente civilizador de la familia y de la sociedad.

La tarea educativa sería llevada a cabo por los maestros, esos artífices oscuros de las sociedades modernas a quienes les era confiado el trabajo más grande que los hombres podían ejecutar, según Sarmiento: terminar la obra de la civilización del género humano que se suponía iniciada en la Antigüedad. Sarmiento igualaba la tarea del maestro a la del sacerdote, ya que ambos promovían el ingreso de nuevos miembros a una comunidad al tiempo que la hacían crecer. De la metáfora del maestro/sacerdote se desprendían otras

\footnotetext{
2 Anales de la Educación Común, Buenos Aires, 1867, X/47: 290.
} 
dos que convertían la herencia en traición educativa: la que asimilaba el agua bendita al silabario y la que equiparaba al pecador con el salvaje. Así, por medio de claras alegorías para el público en general, Sarmiento intentaba transmitir el sentido del magisterio y de la tarea escolar.

Si bien se impondrían los saberes consagrados como elementales por la institución escolar desde el siglo XVI, esto es, la lectura y la escritura, ellos estarían fuertemente asociados a la iniciación a la moral, la formación del carácter, la pulidez de las maneras y la enseñanza de la verdad y de la justicia. Por tanto, la lectura moralizante a través de libros maestros de la virtud fue el propósito de la educación que se fue imponiendo. Transmitir significados acerca de lo escolar implicaba también aludir a los libros como artefactos de la vida moderna y a una institución a la que se consideró socia de la escuela. Por ello, un tema recurrente fue también el de las bibliotecas populares. De hecho, se asignaba un papel estratégico a las bibliotecas populares en términos de formación de una opinión pública favorable a la escuela: los vecinos que pudieran advertir el valor de los tesoros que se podían hallar en las bibliotecas se convertirían luego en defensores de la escuela pública.

Desde la sanción de la Ley 1420 en 1884, que estableció la educación obligatoria, gratuita y gradual, el Estado nacional les exigió a los más importantes protagonistas del mundo educativo de entonces, los inspectores que supervisaban las escuelas de la Capital y los territorios nacionales así como los de las provincias, hacer foco en el control de la materialidad de la escuela - edificios, equipamiento, libros y útiles - así como en la asistencia de los alumnos. Por otro lado, las políticas estatales consideraban que para que la escuela cumpliera su misión era necesario que ingresara la cultura pedagógica del normalismo, esto es, la de las escuelas normales, signada por los valores de disciplina, moral, higienismo, ciencia y vocación de apostolado, a través de docentes especialmente formados en la carrera del magisterio.

En la revista pedagógica La Nueva Escuela ${ }^{3}$, creada en 1893 por Pablo Pizzurno y Alfredo Ferreira, educadores egresados de las primeras escuelas normales, así como en La Escuela Positiva ${ }^{4}$, publicada desde 1895 por Alfredo Ferreira, creador del Comité Positivista Argentino, se postulaba la importancia de la renovación de la enseñanza y del valor de la educación física, de las manualidades, de las ciencias, de la geografía, bajo el supuesto de que la ciencia contemporánea se encontraba fuera de la escuela y que los métodos estaban inmovilizados mientras el mundo cambiaba a su alrededor.

\footnotetext{
${ }^{3}$ La Nueva Escuela, I/1 (Buenos Aires, 1893).

${ }^{4}$ La Escuela Positiva, II/s/n (Buenos Aires, 1896).
} 
Entre las publicaciones que promovieron la cultura del normalismo se encuentra La Educación ${ }^{5}$, órgano de propaganda de la Asociación Nacional de Educación y una de las revistas de mayor circulación hacia fines del siglo XIX. Fundada por José Benjamín Zubiaur, Carlos Vergara y M. Sarsfield Escobar, La Educación fue un periódico quincenal que se dirigía fundamentalmente a los maestros normalistas con el propósito de propagar «buenos métodos de enseñanza» entre un magisterio que crecía en número a lo largo de todo el país. En términos del saber pedagógico, el propio Zubiaur señalaba la importancia del método activo en todas las materias, las excursiones escolares, los juegos atléticos al aire libre, los procedimientos de los trabajos manuales y el establecimiento de cajas de ahorro escolares ${ }^{6}$.

En la batalla, muchos discursos docentes tenían un sesgo defensivo, porque la escuela no estaba libre de ataques ni todo era complacencia con la educación de la época:

«El criminalista busca en los índices de la estadística el acusador del aumento de la criminalidad infantil y lo encuentra en los bancos de la escuela. El sectario religioso les achaca las inmoralidades que se ven sobre la tierra. El socialista la moteja de cruel con los desheredados de la fortuna y la señala como autora del proletariado y de la carencia del pan. Y en resumen: ya como amiga ya como enemiga de la humanidad, la enseñanza es pasto del comentario universal, y de cada fenómeno que se produce en el mundo ella es la causa: post hoc, ergo porpter hoc» ${ }^{7}$.

Sin embargo, proclamaba con optimismo positivista Andrés Ferreira -inspector y autor de uno de los libros más usados en la escuela primaria, El Nene, publicado en 1890 - que el maestro argentino estaba plenamente convencido de su augusta misión apostólica sobre la tierra y que actuaba en función de una consigna sagrada: coronar los ideales de la revolución democrática instruyendo y educando al pueblo para el propio gobierno. Frente a críticas que se solían escuchar por entonces como que en la educación todo era un engaño o una comedia en la que los maestros hacían el papel de payasos y que incluso transmitían vicios a los niños, sostenía que el entusiasmo del maestro se fundaba en una idea nueva en el mundo, transformar la barbarie primitiva en cultura y civilización, y que por eso no lo amedrentaban los temores de un fracaso ni la lentitud de sus obras.

\footnotetext{
${ }^{5}$ La Educación, I/1 (Buenos Aires, 1886).

${ }^{6}$ La Educación, IX/199 (Buenos Aires, 1895): 1176.

${ }^{7}$ La Enseñanza Argentina, II/6 (Buenos Aires, 1897): 113.
} 


\section{LA EDUCACIÓN INVENTA LO SOCIAL COMO NACIÓN}

Transcurrida la primera década del siglo $X X$, en un contexto de creciente influencia de las capas medias y de transformación de los sectores populares, el oficio del magisterio se redefinió, y la cultura escolar, también. Desplazados del primer plano los inspectores, los docentes se convirtieron en las figuras centrales para el propio Estado educador. Igualmente lo fueron para el recién nacido mundo académico de la educación que, preocupado por la cuestión de los métodos, investigó principalmente sobre las prácticas docentes. Asimismo, el desarrollo de una pedagogía práctica con toda su parafernalia alrededor del sostenimiento de la tarea diaria nació para indicarle a los docentes qué hacer y qué materiales usar en el aula, acompañándose esta iniciativa con artefactos como las revistas La Obra y Billiken, las cuales desde los años veinte fueron también artífices de la masificación del sistema educativo. Finalmente, la Iglesia, golpeada en sus atribuciones educativas por la Ley 1420 de 1884, salió a la palestra con fuerza a partir de los años treinta, intentando la consagración de la educación católica a través del llamado «buen maestro», según su propia radiografía.

Probablemente lo más sabido sobre la educación de las primeras décadas del siglo XX es que apuntó a un nacionalismo que la cultura escolar se encargó de codificar. En realidad, fue poco a poco que la formación moral del carácter y los rituales fueron connotando la preparación de las almas nacionales. Bajo la aspiración de que los niños que asistían a las escuelas se interesaran y participaran en las dos grandes fiestas patrias, el Consejo Nacional de Educación estableció hacia 1891 las primeras pautas relacionadas con la celebración de las fiestas patrias. Desde entonces se sucedieron regulaciones que dispusieron que los niños concurrieran obligatoriamente a las escuelas en esos días, que llevaran una pequeña insignia con los colores de la bandera nacional o un pequeño escudo con la armas de la República, que en todas las escuelas y todos los niños cantaran el Himno Nacional, que los maestros explicaran los sucesos históricos y que se trataran los temas históricos en composiciones orales y escritas durante las celebraciones. Sin embargo, en revistas y libros escolares se habilitó un tibio espacio donde apenas se desplegaba el debate alrededor del cosmopolitismo o del nacionalismo. Siguiendo los pasos de la tradición pedagógica que apostaba por la regeneración moral a través de la educación, se creía que la formación de «corazones altruistas» y «caracteres bien templados» serían no solo «el mejor seguro contra el vicio», sino «la base del patriotismo» ${ }^{8}$. Y si bien la enseñanza de la historia patria se fue instalando

\footnotetext{
${ }^{8}$ Revista de Educación, XLI/3 (La Plata, 1915): 770.
} 
progresivamente como contenido nacional, la importancia de la formación moral perduraría, y a ella se asociarían los sentimientos nacionales que irían impregnando prácticas y rituales. Recién en torno al Centenario, y en tiempos en los que el Consejo Nacional de Educación encargaría a Ricardo Rojas el informe del que resultaría su renombrada obra, La Restauración Nacionalista, se comenzaron a establecer rituales nacionales claramente dirigidos al trabajo de la escuela: leer diariamente algún episodio o anécdota histórica de carácter nacional; hacer visibles las efemérides del día con un comentario; iniciar las clases con un canto patriótico; conmemorar con actos «sencillos» — poesías, cantos, composiciones - las fechas importantes de la historia argentina; visitar un museo histórico; visitar monumentos, tumbas y edificios antiguos; disponer y colgar en la escuela retratos de «prohombres», así como cuadros que representen hechos históricos importantes; organizar concursos de composición sobre temas patrióticos entre grados y entre escuelas; leer y recitar fragmentos escogidos de autores nacionales referidos a temas patrios ${ }^{9}$. De la lectura de la prensa educativa en general se desprende que en los años veinte todavía la cuestión de la formación patria o nacional no era un tema dominante, sino que era más relevante en cambio la llamada «moral en acción» como práctica escolar cotidiana, tanto en El Monitor de la Educación, órgano oficial del Consejo Nacional de Educación, como en la revista La Obra, en la cual se promovía la escuela activa y se advertía sobre los peligros de la promoción del sentimiento patriótico por sugestión o imitación colectiva.

En realidad, fue en los años treinta y cuarenta, tiempos de creciente actividad del Estado no solo en la economía sino también en diversas dimensiones sociales, el momento en que la educación hizo de los rituales y ciertos contenidos escolares asociados a la formación nacional su principal razón de ser; del mismo modo, una parafernalia de artefactos comenzó a vincular el día a día de la escuela a las efemérides, con sus liturgias y símbolos nacionales. De hecho, las efemérides patrias se fueron imponiendo en detrimento de la educación moral o de la educación del carácter, tal como solía entendérsela anteriormente.

En el marco de un espacio importante de producción de conocimiento pedagógico comenzó a publicarse en los años treinta el Boletín del Instituto de Pedagogía (Facultad de Ciencias de la Educación de la Universidad Nacional del Litoral), de clara orientación espiritualista, comprometido con las nuevas orientaciones pedagógicas de la escuela nueva. Allí Juan Mantovani, entre otros, incitaba a la reforma de las escuelas normales, criticaba la orientación

${ }^{9}$ El Monitor de la Educación, XXVI/421 (Buenos Aires, 1908): 235-245. 
practicista de los docentes y postulaba que la educación necesitaba de una obra intensiva de cultura antes que de técnicas.

Hacia los años treinta, en relativa consonancia con el clima nacionalista que se vivía, la revista La Obra invitaba a los maestros a generar una nueva pedagogía o didáctica argentina. En 1934, Luis Arena, quien fuera administrador de la revista y secretario de la Sección Argentina de la Liga Internacional de la Nueva Educación, instó a iniciar la construcción de una pedagogía decroliana propia y adecuada a la cultura del país, lo cual suponía revisar las propias prácticas y embarcarse en el cambio que las nuevas orientaciones pedagógicas proponían.

Por su parte, hacia fines de los años treinta, Lorenzo Luzuriaga, pedagogo republicano exiliado de España, continuó en Tucumán con la publicación de la Revista de Pedagogía, fundada en Madrid en el año 1922, la cual se propuso desde 1939 colaborar con la promoción y cambio de la educación a partir de la difusión entre los lectores de las ideas de educadores y pedagogos autorizados sobre la educación nueva y la escuela activa. Por esto, la revista contó con gran cantidad de artículos de representantes del movimiento escolanovista (Dewey, Montesori, Ferriêre, entre otros) cuya característica principal fue el paidocentrismo derivado del naturalismo pedagógico de inspiración rousseauniana y pestalozziana. En la revista era posible encontrar también a quienes se identificaban como pedagogos argentinos: Juan Cassani, lector de Gentile; Luz Vieira Méndez, seguidora de Ferriêre y Decroly, a quienes conoció en Buenos Aires; Olga Cossetini, cuya experiencia educativa en Santa Fe dialogaba con las ideas de Radice y Decroly; Saúl Taborda, pedagogo cordobés que estudió en diversas universidades europeas y opuesto a la tradición sarmientina, pues defendió una educación consonante con la idiosincrasia nativa; o Clotilde Guillén de Rezzano, que introdujo en la Argentina la pedagogía de los centros de interés del pedagogo belga Decroly. Apuntando a la formación intelectual y teórica del magisterio, la Revista de Pedagogía agradecía en 1939 la hospitalidad de la República Argentina, que le permitía volver a salir luego de tres años de interrupción, y afirmaba que no venía a enseñar nada a nadie pero pretendía: «...tener al día a sus lectores del movimiento pedagógico contemporáneo, y en particular del relativo a la educación nueva y a la escuela activa ${ }^{10}$. Este tipo de publicaciones construyó y legitimó nuevas miradas sobre la escuela de la que se hicieron poco a poco eco las escuelas normales que formaban a los docentes. Espacios donde la producción académica se convirtió en bibliografía obligatoria y, por tanto, donde esas miradas tuvieron mucha más vigencia que en las propias universidades.

\footnotetext{
${ }^{10}$ Revista de Pedagogía, I/1 (Tucumán, 1939): 1.
} 
En este clima pedagógico, las publicaciones educativas destinadas a los docentes incluyeron de modo prolífico poemas y versos para los actos escolares; antologías poética para el calendario escolar; prosas para los actos escolares; biografías para la evocación según el calendario escolar; monólogos para las fiestas; relatos dialogados de la historia nacional para representar; retablo escolar o teatro de efemérides; relatos, glosas y apostillas para la evocación; ideas para discursos, monografías y fiestas teatrales; información sobre los símbolos nacionales para que usen los maestros en sus relatos y conversaciones; sugerencias de láminas para acompañar relatos dramáticos nacionales; sugerencias para la confección de escarapelas nacionales; «desarrollos gráficos» para que los alumnos realicen en los cuadernos símbolos, guardas, palmas, objetos históricos y fachadas de edificios históricos; preguntas para conversar sobre los momentos culminantes de la historia nacional; textos o fragmentos para leer y comentar en clase; cuadernos de efemérides; calendario escolar; banderines y señaladores para obsequiar, entre otras propuestas para la escuela que transformaron a la educación de modo notorio.

En relación con el conocimiento del país y el fortalecimiento de la nacionalidad, durante los años treinta y cuarenta resultaron también importantes ciertas tradiciones rurales asociadas al folklore, planteándose la necesidad de modificar la tarea de los maestros en relación con la promoción de bailes, danzas, músicas y canciones. Bajo el supuesto de la falta de documentación e información referente al folklore por parte de las escuelas, se planteó la necesidad de modificar la tarea de los maestros en relación con las tradiciones. Por ello, la Inspección de Educación Física de la Dirección General de Enseñanza Primaria del Ministerio de Educación recientemente creado preparó, en el año 1949, con la colaboración de la Comisión de Folklore y Nativismo de la misma Dirección, unos números especiales de El Monitor de la Educación en los que se explicaban las danzas para la escuela primaria, a partir de una breve reseña y una descripción de los bailes y su coreografía.

Así, la escuela llenó de rituales su vida cotidiana, no solo con la referencia a símbolos sino con una gran acción simbólica, imbricando de un modo magistral acción, pensamiento y emociones. Esto implica que, más allá de la repetición y familiaridad, los rituales producían nuevas acciones y significados en la cultura escolar, ofreciendo además ciertos marcos de expectación. La capacidad del ritual escolar fue muy alta en su intento de alentar significados, de forjar estructuras individuales y comunitarias y de posibilitar ciertas aperturas a otras concepciones y tiempos, convirtiéndose en una poderosa práctica que no solo señalaba una transición cultural, sino que la efectuaba. Los rituales nacionales sostuvieron la ambigüedad entre estabilidad y cambio - ya que en ellos el tiempo se desintegraba y reintegraba procesando tradiciones pasadas 
y definiendo relaciones futuras - y su capacidad fue enorme para constituirse en un medio de apoyo y contención para las emociones intensas, también para facilitar la coordinación entre quienes experimentaban esa transición.

En síntesis, mientras el Estado adoptaba un papel de intervención más acentuada en la economía y en otras esferas de la vida social, como la centralización del sistema de enseñanza a través de la creación del Ministerio de Educación en 1949, y al tiempo que se democratizaba el acceso con una ampliación notable de la matrícula en los niveles primario y medio, la escuela y los docentes inventaban su propio código cultural para metabolizar la llamada cultura nacional y pautaban el ritmo de un proceso que afectó a las generaciones que pasaron por la escuela entre los años treinta y cincuenta.

\section{LA EDUCACIÓN INVENTA LO SOCIAL COMO UN ESPACIO AMOROSAMENTE PLANIFICADO}

Desde los años veinte diversas publicaciones de circulación masiva entre los docentes fueron pactando con sus lectores cambios en la educación. Siguiendo la vía que prestaba atención a «lo natural» en los niños, apelaban a la posibilidad que tenían en sus manos los propios docentes para resolver los problemas del campo educacional. Por tanto, diferenciando a sus lectores de los docentes rutinarios, les proponían y ofrecían pistas para la realización de transformaciones en aulas impregnadas de pedagogía tradicional, a la vez que reconocían en ellos inteligencia y capacidad para discernir e introducir contenidos y modos novedosos de enseñar.

Estas revistas, que militaron por el afecto de los maestros hacia los niños, procedían de diversas canteras afines al escolanovismo: del movimiento anarquista, de la órbita católica, del campo académico, del movimiento asociativo y gremial o del ámbito de la formación docente. Por cierto, desde El Monitor de la Educación, pasando por La Obra, ciertas revistas académicas que se hicieron eco de los postulados de la Escuela Nueva, la revista de tendencia anarquista titulada La Escuela Popular hasta el órgano oficial de la jerarquía de la Iglesia, La Educación Católica, fueron sensibles al paidocentrismo que se fue imponiendo. Ellas requerían que los docentes se dispusieran a ser comprensivos, indulgentes y benévolos con sus alumnos: «Seamos maestros, no seamos vigilantes; hagámonos amigos del niño, ganemos su corazón empleando una buena dosis de paciencia y tolerancia y una más grande de amor» ${ }^{11}$. Propusieron a los maestros cambiar el semblante, los gestos, las expresiones, reemplazando los gritos por sonrisas: «Enseñemos con la sonrisa

${ }^{11}$ La Obra, I/18 (Buenos Aires, 1921): 12. 
en los labios» ${ }^{12}$. Y afirmaban que el trato a los niños debía asentarse en la dulzura de los adultos: «Lo que ha cambiado la escuela en el sentido de la renovación de sus métodos y procedimientos, a estos maestros se lo debe; ellos recorren la senda que al mismo tiempo conduce a la dulzura en el trato de los niños y a la escuela renovada. Tal vez no falte quien piense que esta identificación de la dulzura en el trato de los niños con la escuela renovada sea aquí traída de los cabellos, pero estamos tan convencidos de esa identidad que nos parece la misma evidencia» ${ }^{13}$.

La humildad, la modestia y la sencillez eran cualidades también asociadas al respeto y cariño a los niños y, por tanto, el maestro debía dejar se ser como «Júpiter, esgrimiendo el rayo vengador», para sacarse el «ropaje de dómines infalibles y omnisapientes que se pavonean delante de las pobres criaturas que no pueden llamarlos por sus nombres». Se señalaba, además, que dejar de ser el centro enseñador del aula y adoptar una disposición más expectable y abierta al pedido de consejo por parte de los alumnos solo se lograría por medio de la humildad: «Y, ¿cómo se consigue este desideratum, mi querido amigo? Sencillamente a fuerza de humildad; aprendiendo a esperar, aprendiendo a ver (...) La escuela nueva exige una gran humildad en el maestro, el maestro debe ser el centro de la vida escolar, pero debe pasar inadvertido; debe ser algo así como el punto central del eje de una gran rueda, que permanece invisible, que permanece inmóvil, pero que es el punto de apoyo indispensable para que todo mecanismo que gira en torno suyo se mueva nuevamente, armoniosamente» ${ }^{14}$.

Décadas después ya no fue preciso seguir difundiendo cómo debían comportarse las maestras con los niños. El estereotipo sobre el afecto magisterial se estableció en la cultura y el sentido de dulzura, cariño y calidez alcanzaron su punto máximo como cualidades de la buena docente cuando Abel Santa Cruz estrenó en 1966, en la pantalla del canal 9, Jacinta Pichimahuida, el famoso programa de la maestra de guardapolvo blanco y gesto angelical protagonizado por una ascendente actriz: Evangelina Salazar.

Siguiendo la línea del afecto a los niños, en la prensa educativa de los años sesenta las nociones más frecuentes que se le asocian son las de «crisis» y «cambio». Se trata de tiempos de modernización social y cultural, pero también de ascenso del autoritarismo y de una radicalización política que pone en cuestión los mandatos tradicionales y las relaciones entre las generaciones. La irrupción de los discursos psi en el campo de la educación será una de

\footnotetext{
${ }^{12}$ La Obra, I/18 (Buenos Aires, 1921): 11.

${ }_{13}$ La Obra, XIII/235 (Buenos Aires, 1933): 531.

${ }^{14}$ La Obra, XIII/234 (Buenos Aires, 1933).
} 
las marcas más notables de estos tiempos así como los cambios en la esfera familiar que sacuden la normatividad tradicional. En función de ellos, Eva Giberti llegará a proponer la necesidad de formar a los padres en una Escuela para Padres, que se prolongó como experiencia entre 1956 y 1967 en revistas, diarios, programas radiales y televisivos, cursos y conferencias ${ }^{15}$. Así, con la pedagogización del psicoanálisis la escuela pasará a ser vista como espacio de aplicación de la psicología, o como lugar de interpretación psicoanalítica ${ }^{16}$.

Siguiendo a Spranger, y como discípulos de Juan Mantovani que heredaban su impronta normalista espiritualista, Luis Jorge Zanotti, Alfredo Van Gelderen, Gustavo Cirigliano, Enrique Mayochi, Germán Orduna y Antonio Salonia impulsaron innovaciones metodológicas en la enseñanza y propusieron desde las páginas de Cátedra y Vida ${ }^{17}$, que se publicó entre 1956 y 1970, o desde la Revista del Instituto de Investigaciones Educativas: IIE ${ }^{18}$ que comenzó a publicarse en 1975, la importancia de atender a problemas tales como la comprensión del alumno, las crisis de los adolescentes y el quiebre intergeneracional, en pos de una educación más vital. Ese conjunto de problemas se deslizaría progresivamente en sus artículos a un funcionalismo articulado a partir de la teoría del planeamiento impulsada por los organismos internacionales, requiriendo un planeamiento nacional para la educación del país ${ }^{19}$.

En efecto, los años sesenta implicaron la transformación del espiritualismo liberal en concepciones de vertiente desarrollista y tecnócrata que erigirían la planificación en instrumento clave para solucionar los problemas de la educación. Así, un tipo particular de intervención, la técnica, con la que no habían contado las corrientes espiritualistas, en manos de intelectuales católicos como Zanotti y Van Gelderen, supuso un modo de penetración en el aparato estatal en el contexto de la disputa por imponer contenidos y valores religiosos ${ }^{20}$. El planeamiento educativo, como intervención «despolitizada», continuidad de la tradición liberal de neutralidad de la escuela ${ }^{21}$, tendría también un lugar en Cátedra y Vida a través de artículos de autores como Gilda Romero Brest, Norberto Fernández Lamarra e Inés Aguerrondo ${ }^{22}$. Asociado a necesidades de «planeamiento nacional», se proponían enfatizar la integración social y la capacitación laboral, desde una perspectiva que veía el analfabetismo y la

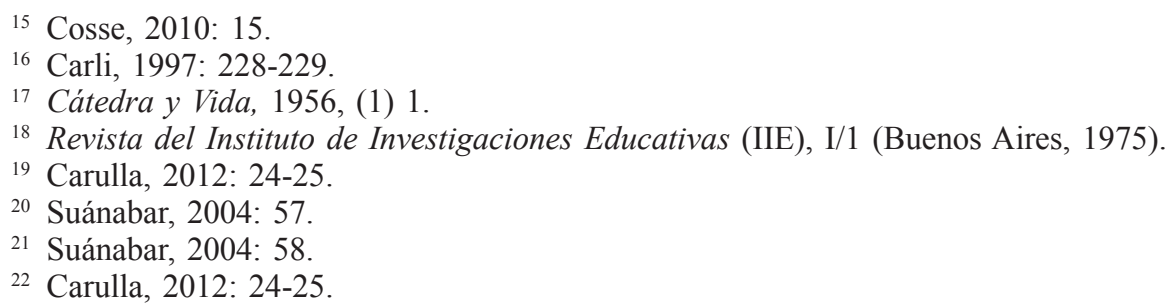


deserción como frenos al desarrollo y la modernización. Antes que vocación se requeriría «profesionalización docente» a través de la «formación» y «capacitación» para superar los problemas educativos detectados y avanzar con el «desarrollo» de la educación.

Por su parte, en los años sesenta también varios editoriales de la revista La Obra observaban con preocupación el retraso de la educación argentina y seguían sosteniendo la necesidad de cambiar. Desde la perspectiva de los editores de la revista, la escuela no había dado pasos significativos en términos de renovación. Siguiendo los lineamientos de Pestalozzi y de Rousseau, de la Escuela Nueva y de la UNESCO, a quien la revista sumó como voz autorizada para orientar la educación, afirmaba: «La escuela, desde la época sarmientina, ya cumplió una importante etapa civilizadora. Pero en este momento tiene un atraso de medio siglo. Pareciera prácticamente paralizada porque, pese a los esfuerzos que desde hace algún tiempo se realizan, son luces de bengala que nacen y se apagan en las esferas burocráticas ${ }^{23}$. Con un plantel renovado, la mayoría procedente de equipos docentes de las escuelas privadas de la ciudad de Buenos Aires donde se desempeñaba el progresismo pedagógico - Escuela Mundo Nuevo, Instituto Sarmiento, Instituto Pestalozzi, Nueva Escuela Argentina 2000 (NEA 2000), Escuela del Sol, Escuela Martín Buber, Escuela Jean Piaget, Instituto Summa - y algunas escuelas públicas e institutos de formación docente de la Ciudad de Buenos Aires, la Provincia de Buenos Aires y la Provincia de Santa Fe — también de vanguardia en el campo de la educación-, la revista que hiciera historia en la renovación de los imaginarios pedagógicos incorporó a su línea editorial el pensamiento de Jean Piaget para sus propuestas didácticas, en tiempos de la dictadura, cuando Piaget era un autor prohibido en los institutos de profesorado ${ }^{24}$. Además de recibir el pensamiento de Piaget con vista a renovar la enseñanza, La Obra introdujo la psicología social para el análisis institucional de los vínculos en la escuela. Asimismo, incorporó el psicoanálisis o el análisis transaccional para el diseño de algunas propuestas de enseñanza.

La revista resultaba inquietante a partir de las propuestas que planteaba para el trabajo en el aula: actos escolares con la participación de padres; dramatización del funcionamiento del corazón a partir de actividades de expresión corporal; ferias de ciencias con experimentos para realizar a lo largo de su recorrido; trabajo con letras de canciones populares como el tango $E l$ aguacero de Cátulo Castillo o Mi niñez de Serrat; indagaciones históricas con cierto tono revisionista en las que importaba, por ejemplo, qué había sucedido

${ }^{23}$ La Obra, XLI/6 (Buenos Aires, 1961): 228.

${ }^{24}$ Caruso y Fairstein, 1997: 157-220. 
durante la Revolución de Mayo en el Noroeste del país antes que en Buenos Aires; recorridos por los subtes de Buenos Aires para conocer a través de las cerámicas de las líneas $\mathrm{C}$ y E diferentes tipos de paisajes; búsquedas del tesoro para aprender los rasgos de la llanura pampeana; orientaciones para la transformación de las bibliotecas escolares en centros multimedios; actividades de escritura expresiva «a lo Cortázar» que permitieran descubrir a los maestros el «dejar escribir»; actividades de expresión libre y de expresión de los sentimientos; actividades pedagógicas para niños de dos años, entre muchas otras.

Desde mediados del siglo XX, los hilos del cambio se entretejieron configurando una textura particular que combinó obsesión con incitación a la mutación en tanto se leía crisis y letargo en la educación. La generación de ese clima de necesidad de mudanzas y transformaciones se expresó en el interrogante sobre qué preservar y qué modificar. Así, algunos alentaron un tipo de trabajo diferente en el aula buscando muchas veces en la didáctica un hechizo que permitiera concretar la ilusión de expandir cuantitativamente el sistema o de exhibir cambios cualitativos, especialmente, ante la necesidad de la democratización de los vínculos hacia adentro de la escuela y de las relaciones sociales hacia afuera, de cara a un proyecto históricamente inacabado para la educación de masas.

\section{LA EDUCACIÓN INVENTA LO SOCIAL COMO UN CORPUS DE SUJETOS VICTIMIZADOS}

En las últimas décadas del siglo algo se quebró: saberes y vínculos sociales se fracturaron en el interior de la escuela. Por cierto, se trata de una tendencia que es posible rastrear con anterioridad. Pero lo que ocurre es que desde entonces el Estado la legitima e institucionaliza. Se concibe un maestro o profesor dedicado a instruir mientras gabinetes, orientadores, tutores y profesionales o expertos de la (psico) pedagogía rodean a la escuela y comienzan a ocuparse del vínculo con los alumnos. Se trata de unas tecnologías que conquistaron el campo de la educación, fragmentando el fenómeno educativo con consecuencias complejas, en el marco de una cultura escolar persuadida por saberes psicológicos propensos a promover la individuación y autonomía de niños y jóvenes. Así, la experiencia educativa y el saber dejaron de tener un sentido vinculante, y con ello, con la pérdida de la idea de lazo, se abandonó progresivamente la pretensión de transformación a partir de la enseñanza, a partir del saber que se ofrece.

En este sentido, puede decirse que la soledad del docente deviene no solo del distanciamiento que supuestamente implican los reclamos que giran a su alrededor procedentes de las políticas públicas, de diversos sectores sociales, 
de las familias y del propio campo de las ciencias de la educación que, por cierto, se ensancharon enormemente en las últimas décadas, sino también de los efectos de la progresiva psicologización de la cultura escolar.

Por otra parte, en el relato de los docentes, la agenda de los medios de comunicación parece constituir una referencia para la construcción de cierta imagen de la escuela. Se trata de una agenda de cuestiones centradas en las noticias desfavorables, catastróficas, excepcionales, que forman parte de una lógica más general de construcción del discurso educativo por parte de los medios de comunicación. En la Argentina sobresalen las cuestiones referidas a las condiciones de infraestructura, a la violencia escolar y a los magros resultados en términos académicos. En este punto, la retórica de los discursos mediáticos plantea un diagnóstico tan catastrófico que incita a los docentes - sujetos victimizados - a requerir que esos problemas educativos se conviertan en una cuestión de Estado y que se lleven a cabo políticas activas y sistemáticas que contrarresten la amargura que produce en ellos la incertidumbre. Pero, el malestar vinculado a un reclamo de acción política en un contexto de desconfianza política genera en el relato de muchos docentes una encerrona que desemboca en una profunda sensación de aislamiento.

Cuando se escucha la voz de los docentes también aparecen múltiples alusiones a las cualidades de los alumnos que parecieran poner en tensión el proceso de transmisión de una generación a otra. La mirada se presenta afectada por variadas sensaciones que van desde la perplejidad, la incomprensión y la vacilación hasta la rigidez, la tirantez y el desprecio de los mayores hacia los que recién llegan y a la nueva cultura que portan. Desde una perspectiva histórico-cultural, los modos de construir la confianza tendrían múltiples aristas $\mathrm{y}$, entre ellas, un complejo trabajo subjetivo - y de largo aliento- - Sin embargo, hoy se expresa mayoritariamente entre el magisterio su antítesis, esto es, la sospecha.

En este marco emerge también, entre quienes enseñan, la sensación de necesidad. Se trata de cierta percepción de los docentes que se traduce requiriendo «algo de donde agarrarse», porque no está cerca ni el directivo, ni la formación continua, ni las políticas públicas, ni las familias, ni la pedagogía. El matiz victimizante del pensamiento educativo remite al reino de las propias necesidades y de las responsabilidades de otros actores, en el marco de un imaginario educativo que se ha ido redefiniendo históricamente y que presenta al docente como un sujeto despolitizado, inerme y desistrumentado en busca protección. La impresión que asumen los propios enseñantes como sujetos privados de ciertas herramientas para enfrentar las diversas situaciones que atraviesan a las escuelas resulta recurrente. Y frente a la inquietud, la lectura de revistas y manuales de autoayuda - la lectura más extendida 
entre los docentes - pareciera tornarse en un sostén que viene a suplir una profunda ausencia.

Por otro lado, la proliferación de la lectura de revistas profesionales con recetas didácticas - Maestra Jardinera, Maestra del Primer Ciclo, Maestra del Segundo Ciclo, La revista del Tercer Ciclo, La revista del Polimodal, Magazine teacher's se vincula a una mayor exigencia en un marco de crisis y empobrecimiento, ya que además de trabajar para traer los mayores ingresos al hogar se encuentran obligadas a asumir el cuidado y la crianza de los hijos, así como otras obligaciones del ámbito doméstico. Lectura percibida como la posibilidad de aproximarse a un material ideal para la mujer-sostén, pues aporta «recetas mágicas» al menú escolar o se convierte en una solución rápida, algo así como el «delivery educativo».

Frente al temor a la muerte, al mal o a lo inmanejable, viejos rituales y prácticas escolares retornan, pero no promovidos por el Estado sino como una táctica inadvertida que vuelven a potenciar los propios docentes en un intento por dar batalla a peligros más o menos genuinos y por reinstalar alguna expectativa que acorrale por un tiempo a los miedos. Esto supone que, ante un futuro confuso y que obsesiona, el pasado se recompone en las prácticas escolares para transmitir su energía y para engullir adversidades a las que el discurso social intentan otorgar vida. Ante la aflicción, suprimir consecuencias, restaurar el viejo orden de cosas, serían algunos de los significados que parecieran rebasar hoy el síntoma en la experiencia cultural en la escuela ${ }^{25}$.

Como intentando contrarrestar la dirección de la fuerza anímica signada por el desborde de problemas de la escuela que muchos docentes enuncian y describen en sus más mínimos detalles, se potencia el anhelo de una escuela idealizada. La cartografía del deseo de muchos maestros pareciera intentar desatarse del discurso actual de los medios de comunicación sobre el deterioro de la infraestructura y la falta de equipamiento escolar; aunque no solo eso, también amarrarse a los viejos sueños de la educación igualitaria ${ }^{26}$.

En una interesante trabajo, Andrea Brito conceptualiza para el caso de los profesores de escuela secundaria argentina el proceso que denomina repliegue identitario. Entre la contención afectiva y la contención del desborde, entre el desorden cultural y el orden moral, observa: «la puesta en acto de ciertos atributos propios de la identidad docente que hoy ya no responden a aquello requerido por la escena escolar. Su baja eficacia es, probablemente, conocida de antemano por los profesores. Sin embargo, eso no debilita sino que, por el contrario, refuerza la convicción sobre su necesidad. De algún modo, aún

\footnotetext{
${ }^{25}$ Finocchio, 2009: 133.

${ }^{26}$ Ossenbach, 2004b: 23-66.
} 
en un suelo de imposibilidad y de incomodidad, es el autosostenimiento lo que está en juego» ${ }^{27}$.

Al mismo tiempo que los temores frenan el ingreso de nuevos artefactos tecnológicos, la idealización romántica de la vieja escuela puede considerarse como una estrategia inconsciente - y limitada - frente a un proceso de flujo $\mathrm{y}$ de transformaciones intensas.

\section{BIBLIOGRAFÍA}

Brito, Andrea, «Los profesores y la escuela secundaria hoy. Notas sobre una identidad en repliegue», Buenos Aires, Libros Libres/FLACSO, 2011. Disponible en http:// libroslibres.flacso.org.ar

Carulla, Valeria, Autoridad pedagógica y culturas docentes en la escuela media Una aproximación desde la revista Cátedra y Vida (1956-1970), Buenos Aires, FLACSO, 2012.

Caruso, Marcelo y Fairstein, Gabriela, «Las puertas del cielo. Hipótesis acerca de la recepción de la psicogénesis y el constructivismo de raíz piagetiana en el campo pedagógico argentino», Adriana Puiggrós (comp.), Historia de la Educación en la Argentina. Dictaduras y utopías en la historia reciente de educación argentina (1955-1983), Buenos Aires, Galerna, 1997: 157-220.

Carli, Sandra, «Infancia, psicoanálisis y crisis de generaciones. Una exploración de las nuevas formas del debate en la educación. 1955-1983», Adriana Puiggrós, Historia de la Educación en la Argentina. Dictaduras y utopías en la historia reciente de la educación argentina. (1955-1983), Buenos Aires, Galerna, 1997: 221-288.

Finocchio, Silvia, La escuela en la historia argentina, Buenos Aires, Edhasa, 2009.

Ossenbach, Gabriela, «La recepción de Pestalozzi en las sociedades latinas», Julio Ruiz Berrio y otros (eds.), La recepción de la pedagogía pestalozziana en las sociedades latinas, Madrid, Ensayos, 2004a: 352-366.

Ossenbach, Gabriela, «Bases para el Avance de la Historia Comparada de la Educación en iberoamérica (Badhicei)», Olga Zuluoga Garcés y Gabriela Ossenbach Sauter, Génesis y desarrollo de los sistemas educativos ibeoramericanos Siglo XIX, Bogotá, Magisterio, 2004b: 23-66.

Suasnábar, Claudio, Universidad e intelectuales: educación y política en la Argentina 1955-1976, Buenos Aires, Manantial, 2004.

${ }^{27}$ Brito, 2008: 26. 
Fecha de recepción: 23/10/12

Fecha de aceptación: 11/1/13

\section{The role of education in the invention of social issues (or how school history progressively transformed social issues in Argentina}

The article examines the period running from mid-19th century to the present, searching for various socio-cultural representations, sensitivities and politics associated with education in Argentina. It's a study on educational press, that focuses on those authors, theories and methods that contributed to school life. Thus, it contrasts pedagogical intentions and school practices through which Argentinian educational system reaches, in its broadest sense, social dimension.

KeYwORDs: Education; Argentina; Teachers; Pedagogy. 